\title{
The heterogeneity of the value of statistical life: Introduction and overview
}

\author{
W. Kip Viscusi
}

Published online: 15 December 2009

(C) Springer Science+Business Media, LLC 2009

\begin{abstract}
The refinement in worker fatality risk data used in hedonic wage studies and evidence from new stated preference studies have facilitated the exploration of the heterogeneity of the value of statistical life (VSL). Although the median VSL estimate for workers is $\$ 7-\$ 8$ million, the VSL varies considerably within the worker population. New estimates of the income elasticity of VSL are 1.0 or above, which are consistent with theoretical models linking VSL to the coefficient of relative risk aversion. The specific relationship between VSL and risk aversion is, however, more complex than previously understood. Age differences in VSL are substantial, with young children being accorded especially high VSL amounts. The public's willingness to pay to reduce risks is reduced if those being protected are perceived as being blameworthy due to their responsibility for contributing to the risk.
\end{abstract}

Keywords Value of statistical life · Fatality risk - VSL · Income elasticity · Blame · Children

JEL Classification $\mathrm{I} 10 \cdot \mathrm{J} 17 \cdot \mathrm{J} 28 \cdot \mathrm{K} 00 \cdot \mathrm{C} 23$

The value of statistical life (VSL) is not a natural constant. Individuals' risk-money tradeoffs vary across the population and also vary over time for particular individuals as their age and economic circumstances change. The heterogeneity of VSL has become more prominent both in terms of economics research and risk policy. Much of the research on the heterogeneity of VSL has been stimulated by the

W. K. Viscusi $(\bowtie)$

Vanderbilt University, 131 21st Avenue South, Nashville, TN 37203, USA

e-mail: kip.viscusi@vanderbilt.edu 
availability of new, comprehensive fatality risk data that make it possible to construct risk variables that are more accurate measures of the worker's job risk than previous measures. There has also been a parallel development of the stated preference literature, which has addressed VSL heterogeneity issues ranging from the role of personal characteristics to blameworthy risky behavior. This special issue of the Journal of Risk and Uncertainty includes four articles that address novel theoretical and empirical issues relating to the heterogeneity of VSL. Here I also summarize the key findings of several other papers that were presented at the Vanderbilt Law School Heterogeneity of the Value of Statistical Life Conference. ${ }^{1}$

\section{The policy context}

Although the application of VSL estimates to provide guidance with respect to policy decisions has not been without controversy, using uniform VSL estimates to monetize the benefits of risk regulations and other policies has become standard practice in the United States and in many other countries. ${ }^{2}$ Other than a few exceptions, the application of VSL estimates in the United States at any time has not extended beyond applying a single VSL number irrespective of the population whose risks are being reduced by the policy.

The principal observed differences in VSL estimates have been over time. Agencies usually increase their VSL amounts as new studies become available, where the VSL rises over time due both to the positive income elasticity of VSL and inflation. Estimates of VSL amounts of \$3 million and sometimes under \$1 million that were used to assess policies in the early 1980s have now been replaced by VSL estimates as high as $\$ 9$ million. ${ }^{3}$ The recognition that changes in societal income have contributed to the increase in VSL has largely been implicit, with no underlying economic mechanism typically being credited for the changes.

Linking increases in the VSL figure for policy analyses to temporal changes in income has proven to be more readily embraced than differentiating VSL amounts across the population at a point in time. Should reducing mortality risks reflect the valuations of those being protected, which will lead to higher VSL amounts for the more affluent? One circumstance in which I have suggested that such differentiation

\footnotetext{
${ }^{1}$ This conference was held at Vanderbilt Law School, March 27, 2009, and was sponsored by the Ph.D. Program in Law and Economics at Vanderbilt University.

${ }^{2}$ These practices were discussed at the conference by former Directors of the U.S. Office of Management and Budget Office of Information and Regulatory Affairs, Susan Dudley and John Graham, and by John F. Morrall, III, former Branch Chief in that office. Other key government participants on this topic were three EPA officials: Brian Mannix, former Associate Administrator for Policy, Economics, and Innovation, Al McGartland, Director, National Center for Environmental Economics, and Alan Carlin, senior economist. Graham (2008) provides a strong articulation of the importance of using VSL estimates for policy assessment based on his tenure directing the regulatory oversight effort.

${ }^{3}$ Viscusi (1992) provides a historical account of my introduction of VSL estimates in U.S. policy contexts as part of the debate over the proposed hazard communication regulation in 1982 using a VSL of \$3 million. Subsequently, the U.S. Dept. of Transportation used VSL levels of $\$ 1$ million or less, but has now increased its VSL to $\$ 5.8$ million. Viscusi (2009) reviews the recent policy debates over adjustments in VSL based on age, income, and more recent economic evidence. The $\$ 9$ million figure is in 2008 dollars and is for the Environmental Protection Agency's 2005 economic analysis for the final stage 2 disinfectants and disinfection byproducts rule.
} 
would be less objectionable is when the beneficiaries of the policy are, in effect, paying for the safety costs themselves. ${ }^{4}$ The only U.S. agency to formalize the possible explicit recognition of income differences in setting the VSL amount either across populations or over time is the U.S. Department of Transportation. That agency now permits the use of an income elasticity adjustment of 0.55 based on the meta analysis of Viscusi and Aldy (2003). ${ }^{5}$ The guidelines did not specify how income considerations might enter.

Many of the concerns regarding VSL as well as the adjustments that agencies make to VSL were reflected in U.S. congressional efforts to influence the agencies' selection of the VSL. Senate Bill S. 3564 that was proposed in 2008 recognized the role of income adjustments, stating that the VSL amount must be increased annually to reflect changes in income. ${ }^{6}$ There was no provision for decreases in VSL if income levels decline, as the proposed legislation stipulated that VSL amounts can be increased but never decreased. This restriction on the direction of adjustments for VSL amounts was stimulated by a downward adjustment in the VSL by the U.S. Environmental Protection Agency (EPA) Air Office from \$7.7-\$7.8 million to \$7.0 million in 2008 dollars. This reduction in VSL figures was based on that office's assessment of the levels of VSL implied by its review of several recent VSL meta analyses. ${ }^{7}$ What was noteworthy about the criticism is that the EPA Air Office numbers remained among the highest in the federal government, and agencies using far lower VSL amounts were not targeted for criticism. The direction of change in the VSL was most influential, as critics fell prey to the anchoring effect and status quo bias of the previous VSL figure. ${ }^{8}$

Income adjustments were not the only target of this congressional initiative. The proposed legislation voiced general discomfort with VSL generally, claiming that "using a dollar value to establish the worth of human life as the basis for making decisions...offends many deeply held religious, moral, and ethical beliefs of people in the United States." The proposed legislation would also ban all recognitions of heterogeneity that reduced the VSL, as the VSL can never be decreased "based on age, income, race, illness, disability, date of death, or any other personal attribute or relativistic analysis of the value of life." While this legislation was never enacted, it does highlight the extreme sensitivity of research pertaining to the heterogeneity of the value of statistical life.

\footnotetext{
${ }^{4}$ Viscusi (1992) provides further discussion of this argument that was developed in support of higher VSL numbers for use by the Federal Aviation Administration.

${ }^{5}$ U.S. Department of Transportation, Office of the Assistant Secretary for Transportation Policy, Revised Departmental Guidance: Treatment of the Value of Preventing Fatalities and Injuries in Preparing Economic Analyses, August 2, 2005. This memorandum cites the Viscusi and Aldy (2003) analysis and uses the midpoint of their estimated income elasticity of VSL range, which they found was from 0.5 to 0.6 based both on their specification of the meta analysis equation as well as when using the equation specifications following four previous studies.

${ }^{6}$ More specifically, VSL must be increased at least once a year to reflect "the average annual total compensation of individuals, including income and benefits." This bill, which was proposed by Senator Boxer, was titled the "Restoring the Value of Every American in Environmental Decisions Act," proposed in the 110th Congress, 2d Session.

${ }^{7}$ In Viscusi (2009) I review and critique the EPA decision to lower the VSL. While proper assessment of the meta analyses did not warrant a downward adjustment in the VSL, there could be circumstances in which a decrease in VSL would be appropriate.

${ }^{8}$ Samuelson and Zeckhauser (1988) discuss such status quo effects in a variety of contexts.
} 
The most prominent aspect of heterogeneity that has been recognized in policy assessments and which has aroused the greatest public controversy is the relation of VSL to age. Policies that reduce mortality risks do not confer immortality but simply reduce the probability of death from specific causes of death. Because individual life expectancy declines with age, the commodity being valued becomes smaller with age. Nevertheless, the person's willingness to pay for reduced risks may not steadily decline with age. ${ }^{9}$ Individual income and consumption exhibit patterns of rising and falling over the life cycle, which is a trajectory that mirrors the estimated pattern of VSL in recent labor market studies. Most recent labor market evidence suggests that the VSL exhibits an inverted U-shaped relationship where the VSL of workers age 60 is higher than that for workers age 20. ${ }^{10}$ This relationship mirrors that of the pattern of lifetime consumption, as one would expect on theoretical grounds and is documented empirically in Kniesner et al. (2006), who analyze the relationship of personal consumption expenditures to VSL.

The VSL-age relationship received national press attention when EPA used a 37\% negative age adjustment in assessing the benefits of the Clear Skies initiative to those who are age 65 and older. ${ }^{11}$ This adjustment was based on surveys in the U.K. indicating age variation in VSL and, while not the first such sensitivity analysis to be undertaken by government agencies, it did receive the most widespread attention. ${ }^{12}$ Application of such a "senior discount," also labeled the "senior death discount," generated an outcry from senior citizen organizations such as AARP. While VSL does eventually decline with age, use of empirical estimates of the VSL-age linkage in Kniesner et al. (2006) found that proper application of evidence on the trajectory of VSL over the life cycle would have little effect on that policy's benefit estimates that would be obtained without any age adjustment.

There seems to have been less controversy in other countries that have recognized the pertinence of age in VSL analyses. Canada has used a $25 \%$ discount to value risk reductions for people over the age of 65, and the European Commission has recommended that the VSL decline with age. ${ }^{13}$

The other end of the age spectrum also merits attention to the extent that risks to the lives of children are valued differently. If, however, the implications of the research are that children should be accorded a higher VSL, which the symposium articles show to be the case, recognition of that heterogeneity is tantamount to

\footnotetext{
${ }^{9}$ With perfect capital markets and annuity markets that enable one to borrow against the present value of one's discounted lifetime income at birth, VSL would decline with age. Most realistic economic models show an inverted-U pattern to the VSL. An early theoretical analysis is that of Shepard and Zeckhauser (1984).

${ }^{10}$ For a review of the labor market studies, see Aldy and Viscusi (2007). Krupnick (2007) provides the counterpart review for survey-based studies. The stated preference studies reflect more inconsistent agerelated patterns than do the labor market studies.

${ }^{11}$ Examples of the discussions of this controversy in the press are "EPA Drops Age-Based Cost Studies," New York Times, May 8, 2003, and "Under Fire, EPA Drops the 'Senior Death Discount," Washington Post, May 13, 2003.

${ }^{12}$ Graham (2008) documents that in the Clinton Administration EPA used the results of two U.K. surveys indicating the appropriateness of age adjustments of $-10 \%$ and $-41 \%$, which it incorporated in its analysis in 2000 of the highway diesel rule.

13 These international practices are discussed in Aldy and Viscusi (2007).
} 
devaluing the lives of adults. How the heterogeneity distinctions are framed may play a pivotal role in determining their acceptability for policy analysis.

The articles in this symposium illuminate the relation of VSL to income, individual job risk levels, risk taking behavior, age, and other personal attributes. Although the articles address specific determinants of VSL estimates, it is useful to combine the factors into two general sources of heterogeneity-differences based on self selection into particular levels of safety for jobs, products, and activities, and differences based on underlying personal characteristics correlated with VSL amounts. From an economic standpoint, the rationale for making distinctions on either of these two dimensions is equally compelling, but the social acceptability of making distinctions based on personal characteristics (e.g., age, race, and income) may be much more controversial than distinctions based on risk taking behavior, such as grossly negligent acts.

\section{Extending the standard hedonic labor market model}

The VSL estimates used for U.S. policy purposes are based on labor market estimates of wage-fatality risk tradeoffs. The hedonic labor market theory underlying these models can be illustrated using Fig. 1. Let W(p) be the market opportunities locus, or the highest wage rate available for any given risk p. Worker 1 chooses the relatively safe job with risk $\mathrm{p}_{1}$, while worker 2 selects the riskier job 2 with risk $\mathrm{p}_{2}$

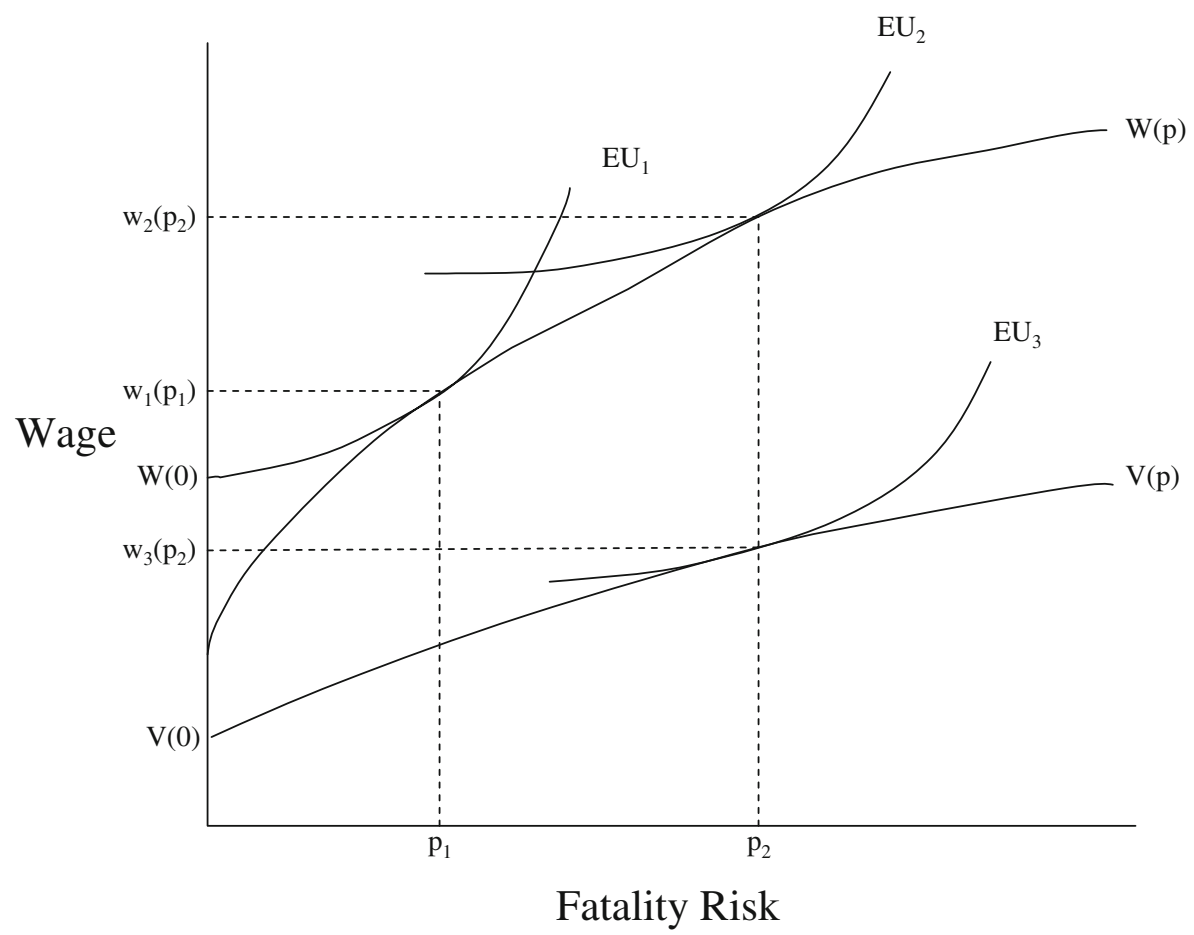

Fig. 1 Hedonic labor market models for risky jobs 
and wage $\mathrm{w}_{2}\left(\mathrm{p}_{2}\right)$. Since the VSL for each worker is the slope of the $\mathrm{W}(\mathrm{p})$ curve at the point of tangency with $\mathrm{EU}_{1}$ and $\mathrm{EU}_{2}$, the worker in the high risk job with risk $\mathrm{p}_{2}$ has a lower VSL than the worker in the low risk job with risk $p_{1}$. The conventional labor market model fits a curve through the locus of these various tangencies.

Research on the heterogeneity of VSL has been greatly stimulated by the development of much more refined labor market data on fatality risks. These data were discussed at the Vanderbilt conference by John Ruser, Assistant Commissioner for Safety, Health, and Working Conditions, U.S. Bureau of Labor Statistics. ${ }^{14}$ The Census of Fatal Occupational Injuries (CFOI) is the first fatality risk data base that provides a comprehensive census of all work-related fatalities. Each fatality is verified using multiple sources such as death certificates, workers' compensation reports, and reports by the Occupational Safety and Health Administration. ${ }^{15}$ These fatality figures can be linked to different employment measures to calculate fatality rates by industry, occupation, age, race, gender, immigrant status, and other dimensions of interest.

Labor market studies usually do not estimate the variation in the VSL with worker risk levels, though there are some exceptions. ${ }^{16}$ The conference paper by Evans and Schaur (forthcoming) and the article by Kniesner, Viscusi, and Ziliak in this issue use quantile regression methods to analyze how the tradeoff rate varies at different quantiles of the wage distribution. As can be seen from Fig. 1, analyzing variations in VSL at different levels of wages also provides information on the variation of VSL with the corresponding risk level. Quantile regressions are used by Evans and Schaur (forthcoming) to simultaneously analyze the effect of earnings heterogeneity and age, and they find that earnings heterogeneity is the more important source of heterogeneity. The conference paper by DeLeire et al. (2009) similarly uses a Roy model to focus on the effect of worker sorting by risk level, finding that this selection process biases estimates of the VSL downward. For all these papers, explicit recognition of the importance of the heterogeneity of VSL using either quantile regressions or a Roy model generates additional insight into the structure of wage compensation for risk.

The core theoretical model underlying labor market studies of VSL is the hedonic wage equation model that fits a curve to the points of tangency to the offer curve W(p) in Fig. 1. Doing so is instructive if workers face the same offer curves, as assumed by the theory. However, this may not be the case. ${ }^{17}$ Suppose that some worker group faces the lower and flatter wage offer curve $V(p)$ in Fig. 1. Worker 3 will choose risk $\mathrm{p}_{2}$ for which that worker's constant expected utility locus $\mathrm{EU}_{3}$ is tangent to the market offer curve. That worker will have a lower VSL than does worker 2 who faces an identical risk but has different market opportunities. One test for such labor market segmentation is whether the compensating differential worker 3 receives for

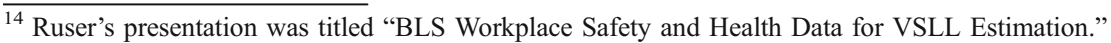

15 The advent of this new risk data greatly diminishes the concerns with measurement error in the fatality risk variable voiced by Black and Kniesner (2003).

${ }^{16}$ Viscusi and Aldy (2003) and Aldy and Viscusi (2007) review the previous labor market studies of variations in VSL with risk levels, income, and age.

${ }^{17}$ Viscusi and Hersch (2001) find that smokers and nonsmokers face different market offer curves, and Viscusi (2003) finds that the offer curves differ by race. Leeth and Ruser (2003) analyze differences in VSL by gender and race.
} 
risk given by $\mathrm{w}_{3}\left(\mathrm{p}_{2}\right)-\mathrm{V}(0)$ is less than what worker 2 receives for the same risk, or $\mathrm{w}_{2}\left(\mathrm{p}_{2}\right)-\mathrm{W}(0)$. Even stronger evidence of such labor market segmentation is if the compensating differential received by worker 3 for risk $\mathrm{p}_{2}$ is below the compensating differential that worker 1 receives for the smaller risk $\mathrm{p}_{1}$ given by $\mathrm{w}_{1}\left(\mathrm{p}_{1}\right)-\mathrm{W}(0)$.

The conference paper by Hersch and Viscusi (2009) explored this segmentation process for legal, recent immigrants. The risk variables they constructed for the analysis included refined measures such as fatality risks based on industry, immigrant status, and age. Non-Mexican immigrant workers have labor market performance that is quite similar to that of native U.S. workers. The average fatality risks for their jobs are almost identical to the rates for native U.S. workers, and the compensating differentials they receive for risk suggest that they are choosing jobs from an offer curve such as W(p) for native U.S. workers. In contrast, Mexican workers face considerably higher risks than native U.S. workers and do not receive statistically significant compensating wage differentials for fatality risk. Mexican workers face greater risk and receive less risk compensation than do other workers, as in the comparison of workers 1 and 3 in Fig. 1. The source of the labor market segmentation appears to be due to differences in language skills. Other factors, such as previous illegal status, are not influential. Such results consequently should serve to highlight the caution that should be exercised in determining the source of the VSL heterogeneity before incorporating such differences in policy assessments.

\section{Overview of conference papers in this issue}

The first paper in the symposium volume, by Kniesner et al. (2010) examines the heterogeneity of labor market estimates of VSL, providing insight into the effects of both income and risk levels on VSL. The article introduces a new econometric method to the VSL literature by employing quantile regression estimates of panel wage equations based on recently developed econometric methods that control for individual heterogeneity in the intercept of quantile regressions. The fixed effect in these quantile regressions controls for person-specific heterogeneity as well as timeinvariant endogeneity. Previously, Kniesner et al. (2008) found that for the standard hedonic wage equation estimated using panel data that latent heterogeneity is a more influential econometric factor than the possible endogeneity of the fatality risk variable. Thus, while the possible endogeneity of the fatality risk variable is a longstanding concern in the labor economics literature, its econometric importance is not great. In contrast, controlling for worker-specific heterogeneity is more consequential, and proves to be consequential for the quantile regressions as well.

The estimated variation in the VSL across the wage quantiles is considerable. Workers at the 0.10 wage quantile who face a fatality risk of eight deaths per 100,000 workers have a VSL of $\$ 3.5$ million (\$2001), while workers at the 0.90 wage quantile with a fatality risk of 4 per 100,000 workers have a VSL of $\$ 22.0$ million. The VSL at the median is $\$ 7.6$ million. Workers with higher wages self select into safer jobs, as reflected in their estimated VSLs. The existence of compensating differentials for risk is not so great as to offset other income-related influences. The income elasticity of VSL is at least 1.0 at all quantile values. 
Regulatory agencies consequently should update the VSL proportionately with increases or decreases in income levels as well as with respect to cross sectional differences in income. These income elasticity estimates exceed those implied by meta analyses of labor market VSL studies, which measure the elasticity across the average tradeoff rates in different studies as opposed to the within sample elasticity estimates presented here.

The Kniesner, Viscusi, and Ziliak article also presents empirical evidence pertinent to the longstanding objection to basing policy assessments on individuals' willingness to pay without accounting for their ability to pay. What if instead of valuing policies based on willingness to pay, the social welfare function valued the marginal value of risk reductions using the same amount for all citizens irrespective of their willingness to pay? Based on the estimates in this paper and the implications of a social welfare function in which marginal reductions in risk are equally valued by all citizens, the authors show that such an approach will be less protective from a risk reduction standpoint than those based on VSL and willingness to pay.

The article in this issue by Evans and Smith (2010) explores the theoretical underpinnings of the income elasticity of VSL both through conceptual models and empirical estimates of some of the key empirical components of such analyses. Previous analyses by Eeckhoudt and Hammitt (2001) and by Kaplow (2005) used simple models to link the income elasticity of the VSL to the coefficient of relative risk aversion (CRRA). Kaplow showed that the CRRA establishes a lower bound on the income elasticity of VSL. There is an apparent inconsistency as theoretically the income elasticity of the VSL should be below the value of CRRA, but with some exceptions such as the Kniesner, Viscusi, and Ziliak article in this issue, most labor market studies of the income elasticity of VSL have not found that to be the case. ${ }^{18}$

The theoretical contribution of the Evans and Smith article is to relax some of the most stringent assumptions of previous models. Their model permits variable labor supply and also recognizes the complementarity between consumption and labor supplied. Even minor modifications of previous models generate ambiguity in the relationship between the income elasticity of VSL and the value of CRRA and, specifically, whether the value of CRRA establishes a floor for the income elasticity of VSL. Further complicating this relationship is that there also may be constraints on labor supply adjustments, such as the consumption commitments associated with one's mortgage payments, which will complicate workers' short run labor supply responses to exogenous shocks.

To explore the potential importance of labor supply responses to exogenous shocks in the presence of consumption commitments, Evans and Smith use data from the Health and Retirement Study. They find strong evidence of the constraining effect of consumption commitments on labor supply adjustments. Mortgage commitments and spousal medical shocks are the two key factors that they examine empirically. These influences separately and in combination affect decisions to exit

\footnotetext{
${ }^{18}$ It should be noted, however, that there are surprisingly few estimates of CRRA in the literature and considerably more estimates of the income elasticity of VSL, typically based on meta analyses of labor market VSL studies.
} 
the labor force, bolstering their advocacy of a more general theoretical model than adopted in previous studies.

The other two articles in this symposium volume utilize stated preference survey methods to value risk reductions. Hammitt and Haninger (2010) presented subjects with a risk context involving pesticide residues on food. The substantive economic issues of interest pertained to respondents' willingness to pay for reductions in the risk of death and trauma to the adults and children in the household. A chief benefit of the survey approach as opposed to labor market studies is that it provides evidence regarding risk reductions for people outside the labor force, particularly for children. To ensure that respondents were cognizant of the risks to family members other than themselves, the survey presented risk scenarios that focused on the risks to children.

The Hammitt and Haninger survey yielded estimates of VSL for adults of $\$ 6$ million to $\$ 10$ million that are quite similar to those found in labor market studies of adult workers. The valuation of risks to children's lives yielded estimates roughly double in magnitude, from $\$ 12$ million to $\$ 15$ million. These high values represent the altruistic concerns of the parents with children's well-being. If, as a policy approach, the parental values of VSL serve as the VSL measure up to age 18 and the person's own VSL estimate is used thereafter, then used in conjunction with the labor market evidence in Aldy and Viscusi (2007) there will be a drop in VSL at age 18 , followed by a subsequent increase. Parents apparently place a greater protective value of a child's life than the children will place on their own lives once they reach adulthood. Such a relationship may be a consequence of the combined influence of altruism and the income elasticity of VSL as parents are more affluent than their children will be at age 18 .

That there may be such non-monotonic age-related patterns in the VSL implied by the Hammitt and Haninger valuations of children's lives in conjunction with labor market evidence is borne out in the conference paper by Blomquist et al. (2009). They analyze willingness to pay to prevent fatal adverse reactions from asthma medications. They find that the VSL peaks for young children and then declines until about age 30 after which it rises until age 66 before beginning a decline. The observed pattern for those of working age generally follows the inverted-U shaped pattern of labor market studies. This curve for adults is then augmented by their results for the younger age groups for which they find a pattern of declining VSL values from the early childhood peak.

The utilization of the stated preference survey approach enables Hammitt and Haninger to explore determinants of VSL linked to economic theory. While the latency period has no significant effect on willingness to pay in their study, contrary to economic theory, there is a positive effect on VSL of the measure of risk aversion based on individuals' stated levels of risk aversion. ${ }^{19}$ This result provides support for the economic analyses linking risk aversion and VSL, but does not have implications regarding the relative magnitude of the income elasticity of VSL and CRRA, which hinge on the specific model assumptions.

\footnotetext{
${ }^{19}$ Other measures of risk aversion were not significantly related to the willingness to pay values.
} 
The final article in this issue, by Covey et al. (2010) explores the results of two stated preference surveys regarding railway safety in the United Kingdom. Their focus is not on individuals' willingness to pay to prevent risks to themselves but rather on societal valuations of reduced risks of death from various kinds of railway accidents, some of which may of course be risks to which the individual is exposed as well. Thus, the money-fatality risk tradeoffs being considered are not comparable to those in the other papers because they are from a quite different perspective.

A major theme of their study is that the value people place on reducing risks is not uniform. The main difference that their paper focuses on is that individual culpability that led to the person's risk exposure affects the public's willingness to prevent the accident. At one extreme, passengers who are the victim of a derailment clearly did not contribute to the accident, whereas trespassers or suicides involve a greater degree of culpability. The authors also distinguish accidents for adults and for children. Particularly for adults, irresponsible behavior reduces the societal value, but this differential is less pronounced for children at risk. A distinction between the culpability of adults and children is also made by most legal systems throughout the world.

Why people value saving the lives of those who are responsible for taking the risk and are viewed as being more blameworthy could be due to a variety of reasons. To the extent that people have chosen very high risks through their contributory negligence, they have shown that they personally may have a low VSL. If the prospective victims have a low VSL, then others may reason that society too might value risks to their lives less. It is noteworthy, however, that the scenarios considered all involved revelation of low VSLs through reckless behavior rather than being the result of economic hardships that lead one to accept a dangerous job. Another possible contributory factor to the difference in the valuations of the risk reductions is that the public generally is unwilling to provide assistance in situations in which they believe that there is substantial moral hazard. Viscusi and Zeckhauser (2006) found that after Hurricane Katrina that the public's willingness to assist future hurricane victims was substantially diminished if people chose to move back to areas that would expose them to future hazards.

For U.S. policy decisions, the voluntary/involuntary risk distinction has not been linked to adjustments for blameworthiness but rather has arisen most frequently in discussions of broadly based environmental risks. ${ }^{20}$ People who choose to work on dangerous jobs are a self selected group that is willing to bear risk, and EPA officials suggest that the VSL numbers used to protect people exposed to environmental hazards are not subject to the same self selection biases. Whether there should be any adjustment for voluntary and involuntary risks depends on both the labor market study reference point and the characteristics of the environmental risk. If the VSL reference point is the average VSL for a broadly representative worker group rather than workers in very high risk jobs, the use of labor market estimates may be

\footnotetext{
${ }^{20}$ This distinction also arises in Section 4A of the bill S. 3564 introduced by Senator Barbara Boxer in 2008, 110th Congress, 2d Session, the "Restoring the Value of Every American in Environmental Decisions Act." However, that legislation proposes a premium for involuntary risks rather than a deduction for voluntary risks.
} 
reflective of the VSL for the protected population. Also, just as workers may choose jobs based on their wage-risk tradeoffs, for many environmental conditions such as air pollution and hazardous waste, people likewise make a housing priceenvironmental risk tradeoff so that there are analogous market processes and self selection effects at work.

While there have been many pleas for using higher VSL amounts for involuntary risks, we know of no policymakers who have advocated using lower VSL amounts for people who have chosen to incur large risks. Should we use the same average societal VSL to evaluate safety regulations for those in extremely risky jobs with annual fatality risks of $1 / 1,000$, or for regulations affecting cigarette smokers, drunk drivers, or people who have chosen to live in highly polluted areas? There is a clear asymmetry in the willingness of policymakers to draw distinctions.

\section{Policy prospects for incorporating the heterogeneity of VSL}

The two aspects of VSL heterogeneity that have received the most economic analysis are differences by income and by age. Each of these adjustments has had limited use in policy evaluations. The effect of income on VSL is straightforward, as higher income boosts the VSL, while the influence of age is more complex.

Reducing risks to life is a normal good with a positive income elasticity. The magnitude of the elasticity is 0.5 to 0.6 based on meta analyses of labor market studies. But these studies are not ideally suited to capturing the variation of the elasticity across the entire wage spectrum. There tends to be only modest variation in the typical worker captured in such studies. Focusing on the average worker across studies suppresses much of the elasticity variation. At the extreme 0.10 quantile, Kniesner, Viscusi, and Ziliak found that the income elasticity is 2.24, while lower income elasticities closer to 1.0 were found at the upper quantiles. Their empirical evidence is consistent with simple theoretical models of risk aversion and VSL indicating that the income elasticity of VSL implies that the VSL should increase proportionately with income if the CRRA is around 1.0.

The influence of age on VSL is not monotonic. At the bottom of the age spectrum, the VSL appears to be high, where this value is based on parents' altruistic concerns for their children. Beyond that age range, there is an inverted- $U$ shape to the VSL for adults, but the decline in VSL at very old age groups does not appear to be stark. One possible exception might be for people with extremely short remaining life spans, such as those with terminal illnesses, for whom one could use the value of statistical life year measure to assess the benefits of reducing their risks. ${ }^{21}$

There will be efficiency gains if policies can be targeted to reflect the well established evidence regarding the heterogeneity of VSL. Suppose that there are two types of transportation safety policies, improved guardrails that affect a broad mix of the population and airline safety regulations that affect higher income citizens.

\footnotetext{
${ }^{21}$ People with severe respiratory ailments and little expected remaining life often are those who benefit from air pollution regulations. For such populations, one might value the benefits using the value of statistical life year measure. The value of statistical life year approach was advocated at the conference by Brian Mannix.
} 
Utilizing VSL estimates that incorporate the positive income elasticity of VSL will lead to regulations with a higher expected cost per life saved for airline safety regulations. The resulting regulations will also be in line with the respective willingness to pay of the populations protected. Particularly if airline passengers pay for the greater safety levels through higher ticket prices, there should be few valid reasons for any equity concerns.

However, what if those protected by guardrails have below average VSL levels and those protected by airline safety regulations have above average levels? While the efficient policy regime would structure the regulations to reflect the willingness to pay of the protected populations, one alternative is to establish a floor on the VSL equal to the population average. Guardrail policies will be designed using the average societal VSL, while airline safety policies can use a higher VSL. This approach will use a higher average VSL for policy assessment than the actual population average but will lead to appropriate stringency of airline safety regulations and no greater inefficiency of guardrail regulations than would be the case if all policies were assessed using the same average societal VSL. This imperfect hybrid policy consequently will be superior to ignoring heterogeneity altogether.

Framing the heterogeneity adjustment may have a critical effect on its appeal. Income adjustments for increasing the VSL over time or in recognition of the higher values of future generations are generally viewed favorably, while the equivalent adjustments for income differences at a given period of time are not. Similarly, using a lower VSL for some age groups may strike some as morally offensive, but failure to make such adjustments will result in inordinately large differences in the value per statistical life year for these different age groups, which is a different form of inequity. Incorporating the heterogeneity of VSL in policy assessments remains an ongoing challenge. However, so long as there remain considerable imbalances between the cost effectiveness of policies and average VSL amounts, progress with respect to incorporating the heterogeneity of VSLs is of subsidiary importance to the more fundamental quest for rational risk policies.

Wholly apart from political feasibility, whether there should be recognition of the heterogeneity of VSL for policy purposes depends critically on the source of the heterogeneity. Mexican immigrants have lower VSLs than the rest of the working population, but that is due to the limited English language skills of some of these immigrants who face different market opportunities. Much the same is true for African American workers. Why there are such differences in labor market opportunities merits further exploration. If the observed differences are attributable to a market failure, such as labor market discrimination, then incorporating these VSL differences in policy evaluations is unwarranted. Similarly, differences by gender may arise because women have lower wages on average. VSL estimates derived from the standard log wage equations are a linear function of wages and the fatality risk coefficient. Unless the fatality risk coefficient is larger for women, which studies have not shown is the case, then women will have a lower estimated VSL.

There is substantial reluctance to make VSL estimates conditional on personal characteristics such as gender, race, and ethnicity. Qualms about differentiating the VSL along these dimensions may have a sound economic basis. Before fully incorporating the implications of results pertaining to heterogeneity of VSL based on 
the person's demographic profile, there generally is the need to explore further the economic mechanisms that give rise to the heterogeneity.

\section{References}

Aldy, J. E., \& Viscusi, W. K. (2007). Age differences in the value of statistical life: revealed preference evidence. Review of Environmental Economics and Policy, 1(2), 241-260.

Black, D. A., \& Kniesner, T. J. (2003). On the measurement of job risk in hedonic wage models. Journal of Risk and Uncertainty, 27(3), 205-220.

Blomquist, G. C., Dickie, M., \& O'Conor, R. M. (2009). Willingness to pay for improving fatality risks and asthma symptoms: values for children and adults of all ages. University of Kentucky Working Paper, forthcoming in Resource and Energy Economics.

Covey, J., Robinson, A., Jones-Lee, M., \& Loomes, G. (2010). Responsibility, scale and the valuation of rail safety. Journal of Risk and Uncertainty, 40(1).

DeLeire, T., Khan, S., \& Timmons, C. (2009). Roy model sorting and non-random selection in the valuation of statistical life. Working Paper, Duke University.

Eeckhoudt, L. R., \& Hammitt, J. K. (2001). Background risk and the value of a statistical life. Journal of Risk and Uncertainty, 23(3), 261-279.

Evans, M. F., \& Schaur, G. (forthcoming). A quantile estimation approach to indentify income and age variation in the value of statistical life. Journal of Environmental Economics and Management.

Evans, M. F., \& Smith, V. K. (2010). Measuring how risk tradeoffs adjust with income. Journal of Risk and Uncertainty, 40(1).

Graham, J. D. (2008). Saving lives through administrative law and economics. University of Pennsylvania Law Review, 157, 395-540.

Hammitt, J. K., \& Haninger, K. (2010). Valuing fatal risks to children and adults: effects of disease, latency, and risk aversion. Journal of Risk and Uncertainty, 40(1).

Hersch, J., \& Viscusi, W. K. (2009). Immigrant status and the value of statistical life. Vanderbilt Law and Economics Working Paper SSRN 1394360, forthcoming in Journal of Human Resources.

Kaplow, L. (2005). The value of a statistical life and the coefficient of relative risk aversion. Journal of Risk and Uncertainty, 31, 23-34.

Kniesner, T. J., Viscusi, W. K., \& Ziliak, J. P. (2006). Life-cycle consumption and the age-adjusted value of life. Contributions to Economic Analysis \& Policy, 5(1), 1-34.

Kniesner, T. J., Viscusi, W. K., Woock, C., \& Ziliak, J. P. (2008). The value of a statistical life: evidence from panel data. Working Paper, Syracuse University. http://gatton.uky.edu/Faculty/ziliak/ KVWZ_VSL.pdf

Kniesner, T. J., Viscusi, W. K., \& Ziliak, J. P. (2010). Policy relevant heterogeneity in the value of statistical life: new evidence from panel quantile regressions. Journal of Risk and Uncertainty, 40(1).

Krupnick, A. (2007). Mortality-risk valuation and age: stated preference evidence. Review of Environmental Economics and Policy, 1(2), 261-282.

Leeth, J. D., \& Ruser, J. (2003). Compensating differentials for fatal and nonfatal injury risk by gender and race. Journal of Risk and Uncertainty, 27(3), 257-277.

Samuelson, W., \& Zeckhauser, R. J. (1988). Status quo bias in decision making. Journal of Risk and Uncertainty, 1, 7-59.

Shepard, D. S., \& Zeckhauser, R. J. (1984). Survival versus consumption. Management Science, 30, 423-439.

Viscusi, W. K. (1992). Fatal tradeoffs: Public and private responsibilities for risk. New York: Oxford University Press.

Viscusi, W. K. (2003). Racial differences in labor market values of a statistical life. Journal of Risk and Uncertainty, 27(3), 239-256.

Viscusi, W. K. (2009). The devaluation of life. Regulation and Governance, 3, 103-127.

Viscusi, W. K., \& Hersch, J. (2001). Cigarette smokers as job risk takers. Review of Economics and Statistics, 83(2), 269-280.

Viscusi, W. K., \& Zeckhauser, R. J. (2006). National survey evidence on disasters and relief: risk beliefs, self-interest, and compassion. Journal of Risk and Uncertainty, 33(1/2), 13-36.

Viscusi, W. K., \& Aldy, J. E. (2003). The value of a statistical life: a critical review of market estimates throughout the world. Journal of Risk and Uncertainty, 27(1), 5-76. 